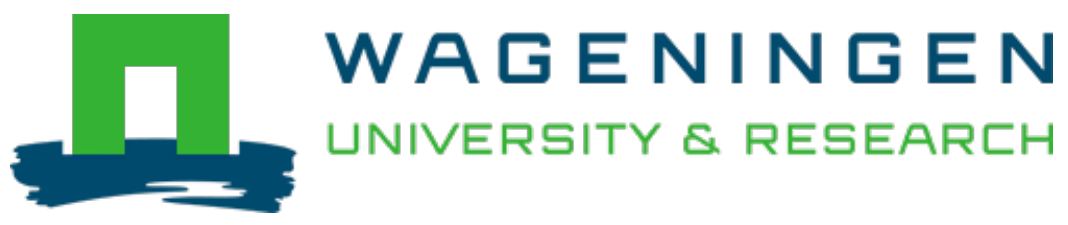

\title{
Chemical and sensory changes during shelf-life of UHT hydrolyzed-lactose milk produced by "in batch" system employing different commercial lactase preparations
}

\author{
Food Research International \\ Bottiroli, Riccardo; Dario Troise, Antonio; Aprea, Eugenio; Fogliano, Vincenzo; Vitaglione, Paola et al \\ https://doi.org/10.1016/j.foodres.2020.109552
}

This article is made publicly available in the institutional repository of Wageningen University and Research, under the terms of article $25 \mathrm{fa}$ of the Dutch Copyright Act, also known as the Amendment Taverne. This has been done with explicit consent by the author.

Article 25 fa states that the author of a short scientific work funded either wholly or partially by Dutch public funds is entitled to make that work publicly available for no consideration following a reasonable period of time after the work was first published, provided that clear reference is made to the source of the first publication of the work.

This publication is distributed under The Association of Universities in the Netherlands (VSNU) 'Article $25 \mathrm{fa}$ implementation' project. In this project research outputs of researchers employed by Dutch Universities that comply with the legal requirements of Article 25fa of the Dutch Copyright Act are distributed online and free of cost or other barriers in institutional repositories. Research outputs are distributed six months after their first online publication in the original published version and with proper attribution to the source of the original publication.

You are permitted to download and use the publication for personal purposes. All rights remain with the author(s) and / or copyright owner(s) of this work. Any use of the publication or parts of it other than authorised under article $25 \mathrm{fa}$ of the Dutch Copyright act is prohibited. Wageningen University \& Research and the author(s) of this publication shall not be held responsible or liable for any damages resulting from your (re)use of this publication.

For questions regarding the public availability of this article please contact openscience.library@wur.nl 
Monograph

\title{
Chemical and sensory changes during shelf-life of UHT hydrolyzed-lactose milk produced by "in batch" system employing different commercial lactase preparations
}

\author{
Riccardo Bottiroli $^{\mathrm{a}, \mathrm{b}}$, Antonio Dario Troise ${ }^{\mathrm{b}, \mathrm{c}}$, Eugenio Aprea ${ }^{\mathrm{a}, \mathrm{d}, *}$, Vincenzo Fogliano $^{\mathrm{e}}$, \\ Paola Vitaglione ${ }^{\mathrm{b}}$, Flavia Gasperi ${ }^{\mathrm{a}, \mathrm{d}}$ \\ ${ }^{a}$ Department of Food Quality and Nutrition, Research and Innovation Centre, Fondazione Edmund Mach, via E. Mach 1, 38010 San Michele all'Adige, TN, Italy \\ ${ }^{\mathrm{b}}$ Department of Agriculture and Food Science, University of Naples, Federico II, 80055 Portici, NA, Italy \\ ${ }^{\mathrm{c}}$ Proteomics \& Mass Spectrometry Laboratory, ISPAAM - CNR, 80147 Naples, Italy \\ ${ }^{\mathrm{d}}$ Center Agriculture Food Environment University of Trento/Fondazione Edmund Mach, via E. Mach 1, 38010 San Michele all'Adige, TN, Italy \\ ${ }^{\mathrm{e}}$ Food Quality \& Design Group, Wageningen University, PO Box 8129, 6700 EV Wageningen, the Netherlands
}

\section{A R T I C L E I N F O}

\section{Keywords:}

Hydrolyzed-lactose milk

Amino acids

Off flavor

Strecker degradation

Lactase preparations

\begin{abstract}
A B S T R A C T
Manufacturing shelf-stable Ultra-high temperature hydrolyzed-lactose milk (UHLM) is a challenge for dairy producers, as the product undergoes chemical changes during storage due to both reducing sugars reactivity and proteolysis arising from the impurity of the lactase preparations. In the present study, the "in batch" production system, which includes the addition of the lactase before the thermal treatment, was demonstrated a valuable alternative to the more popular "in pack" system, where lactase is added directly into each milk package after thermal sterilization. The features of the technology were investigated by monitoring the changes in free amino acids, volatile organic compounds, color and sensory properties of UHLMs produced with three different lactase preparations (LPs), up to 120 days at $20{ }^{\circ} \mathrm{C}$. Upon UHT processing, the proteolytic side activity of lactases was minimized, so minimum breakdown of milk protein was achieved. The release of free amino acids was dependent on the lactase purity only in the early production phases, whereas it did not change over time. The Strecker aldehydes benzaldehyde and 2-methylbutanal resulted as effective markers to correlate with the initial lactase purity during storage. Color and sensory slightly changed during storage but were poorly correlated with the different lactases, resembling to phenomena typical of milk aging. This latter result suggested that production costs might be lowered by opting for less-purified lactases when considering the "in batch" technology, supporting the application of this production system for the design of UHLM with high-quality standards and low risk of alterations during shelf-life.
\end{abstract}

\section{Introduction}

Many consumers avoid lactose-containing products as a consequence of discomfort related to lactose digestion (Sahin, Hamamci, \& Garayev, 2016). Upon weaning, the activity of intestinal lactase significantly decreases, hampering lactose hydrolysis in subjects with low levels of lactase persistence (Itan, Jones, Ingram, Swallow, \& Thomas,
2010). With an estimated $70 \%$ world population suffering of lactase deficiency, low-lactose (LLM) and lactose-free (LFM) milk products are the most convenient solution to face lactose intolerance (Deng, Misselwitz, Dai, \& Fox, 2015).

Manufacturing of LLM and LFM is based on the hydrolysis of lactose into glucose and galactose by addition of soluble lactase (Jelen \& Tossavainen, 2003). Since the two monosaccharides increase the

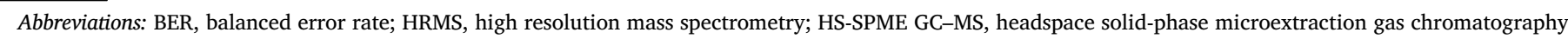

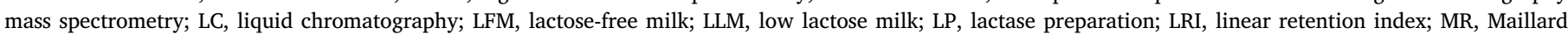

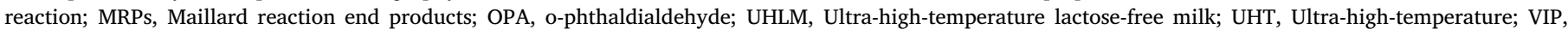
variable importance in prediction

* Corresponding author at: Department of Food Quality and Nutrition, Research and Innovation Centre, Fondazione Edmund Mach, via E. Mach 1, 38010 San Michele all'Adige, TN, Italy.

E-mail addresses: riccardo.bottiroli@fmach.it (R. Bottiroli), antoniodario.troise2@unina.it (A. Dario Troise), eugenio.aprea@fmach.it (E. Aprea), vincenzo.fogliano@wur.nl (V. Fogliano), paola.vitaglione@unina.it (P. Vitaglione), flavia.gasperi@fmach.it (F. Gasperi).
} 
perceived sweetness of the milk, filtration is sometimes introduced to reduce the concentration of lactose prior to the enzymatic conversion (Harju, Kallioinen, \& Tossavainen, 2012). At the same time, lactose hydrolysis doubles the reducing sugar molarity in the milk favoring Maillard reaction (MR) (Tossavainen \& Kallioinen, 2007). In the case of severe thermal treatment, such as those occurring in Ultra High Temperature (UHT) processing, chemical modifications on proteins occur and advanced Maillard reaction products (MRPs) are formed (Troise et al., 2016). The proteolytic side activity of the lactase preparation (LP) increases the amount of free amino group in the milk and consequently the formation rate of volatiles MRPs (Jansson, Clausen, et al., 2014a). Therefore, MR proceeds more extensively in UHT hydrolyzedlactose milk (UHLM) compared to regular UHT milk (Jansson, Clausen, et al., 2014). This higher sensitivity towards non-enzymatic browning is the main reason why producers have shorten the commercial shelf-life of the product down to $90-120$ days.

This is a big limiting factor for European manufacturers to export their UHLMs overseas. The request for dairy products in Asian countries is increasing dramatically (Fuller, Huang, Ma, \& Rozelle, 2006) and, with a majority of the population lactose intolerant, UHLM is a profitable opportunity to fill the demand (Jansson, 2014). On the other hand, temperature fluctuations during transportation as well as quarantine periods during customs checks are frequent when products are traded to a different country. In this harsh environment, MR proceeds extensively in UHLM increasing the risk of quality losses before the product reaches the final destination. Developing UHLM with shelf-life close to regular UHT milk (9-12 months) will facilitate the distribution (Nielsen et al., 2017), but answers to the critical factors limiting the UHLM shelf-life are also related to a deep understanding of the technology employed for production and the associated chemical modifications.

Two main production systems, commonly called "in batch" and "in pack", are currently available for UHLM production with soluble LP, as recently outlined by Dekker and coworkers (2019). The "in batch" production system starts with the addition of the LP in tank and the incubation of the milk at refrigerated conditions. The enzyme is then inactivated by UHT treatment before bottling. In the "in pack" process, LP is instead added directly into each milk package, after the UHT treatment. As lactose hydrolysis occurs after packaging, the production system reduces the overall cost of production by lowering the amount of enzyme required (Troise et al., 2016). The aseptic packaging technology facilitated the diffusion of the "in pack" system among producers as demonstrated by the number of research articles published on the milk produced following this procedure (Jansson, Clausen, et al., 2014; Jansson, Jensen, Sundekilde, et al., 2014; Jensen et al., 2015; Zhao et al., 2019).

Nevertheless, this production system has also negative aspects to consider. For example, LP is not inactivated so its proteolytic side activity can cause unpleasant quality defects in the milk during shelf-life (Jansson, Jensen, Sundekilde, et al., 2014). The quality of UHLM produced by "in pack" system has been largely investigated focusing on lysine blockage, peptide release, formation of unwanted volatile organic compounds (VOCs) and sensory properties (Jansson, Clausen, et al., 2014; Jansson, Jensen, Sundekilde, et al., 2014; Jensen et al., 2015; Nielsen et al., 2017, 2018; Troise et al., 2016). Nielsen and coworkers (2018) paralleled the quality of the "in pack" UHLM to the initial proteolytic activity of the commercial LP, hence the modifications occurring during the shelf-life are the key target of research efforts. In this frame, although authors prioritized the employment of the "in pack" system to control MR in UHLM (Mendoza, Olano, \& Villamiel, 2005), production by "in batch" system is a valid alternative to minimize the defects due to excessive proteolysis and MRPs formation in the final product.

Partial survival of the LP proteases after UHT treatment was previously reported (Tossavainen \& Kallioinen, 2007). As a matter of fact, the literature lacks of detailed studies concerning the effect of different
LPs on the quality of UHLM obtained by this particular production system. Thermally-induced modifications occurring in the milk added with LP before UHT treatment are still unclear and the effects on the final product quality still unexplored. Accordingly, the purpose of this study was to investigate the impact of different commercial LPs on the proteolysis, the volatile organic compounds (VOCs) evolution, the color alteration and the changes in sensory perception in UHLM produced by the "in batch" production system during shelf-life.

\section{Material and methods}

\subsection{Chemicals}

Acetonitrile and water for liquid chromatography high resolution mass spectrometry (LC-HMRS) analysis were obtained from Merck (Darmstadt, Germany). Formic acid, the analytical standards [4,4,5,5$d_{4}$ ]-L-lysine hydrochloride ( $d_{4}$-Lys), L-Lysine-6- ${ }^{13} \mathrm{C}$ dihydrochloride (13C-Lys), 4-methyl-2-pentanone (purity $\geq 99 \%$ ) and the 20 L-amino acids analytical standards were purchased from Sigma-Aldrich (St. Louis, MO). O-phthaldialdehyde (OPA) and dithiothreithol for the OPA method were purchased from Sigma-Aldrich (St. Louis, MO). Disodiumtetraborate-Decahydrate and sodiumdodecylsulfate were obtained from Merck (Darmstadt, Germany). Nilac low-heat skim milk powder was acquired from NIZO Food Research (Ede, The Netherlands).

\subsection{Milk samples production and shelf-life study}

Three commercial LPs (LP1, LP2 and LP3) were tested in the experiment. The three LPs were obtained in the form of a liquid with a shelf-life of 24 months each at refrigeration conditions. All the tested LPs were purified from Kluyveromyces lactis and had an average enzymatic activity reported on the technical sheet higher than $5000 \mathrm{NUL} / \mathrm{g}$. LP3 was an extended purified version of the enzymatic preparation LP2.

Manufacturing of UHLM occurred at industrial level following the "in batch" operating conditions described by Troise et al. (2016). Samples were produced starting from semi-skimmed pasteurized milk. Production was repeated three times for each LP tested, starting from milk always having the same composition, in order to include an estimation of the batch-to-batch milk variability. Each LP was added to the milk to reach an approximate enzymatic concentration of $3000 \mathrm{NUL} / \mathrm{L}$ milk. Lactose hydrolysis was performed in tank at refrigerated conditions and took approximately $25-35 \mathrm{~h}$ for all the lots of production. Lactose was monitored according to the method previously described by our group (Troise et al., 2016) and, at the end of the hydrolysis step, the residual lactose content was $<0.1 \mathrm{~g} / 100 \mathrm{~mL}$ milk. Milk was then supplied to direct UHT processing and, after homogenization and cooling, it was packed aseptically. The same operating conditions were applied to each industrial production. At the end of each production batch, the time 0 of analysis was taken, whereas the rest of the samples were placed into a climate chamber set at $20{ }^{\circ} \mathrm{C}$. The shelf-life study lasted in 120 days with samples collected every 30 days and stored at $-80{ }^{\circ} \mathrm{C}$ until analysis.

\subsection{Free amino group}

The proteolytic activity was determined with Nilac low-heat skim milk powder as substrates. The newly-formed amino groups were detected after derivatization with o-phthaldialdehyde (OPA). Reconstituted milk (25 g/L) was pre-incubated at $37{ }^{\circ} \mathrm{C}$ for $5 \mathrm{~min}$. The enzymatic reaction was started by adding $0.2 \mathrm{~mL}$ enzyme solution to $1 \mathrm{~mL}$ reconstituted milk, and terminated by adding the OPA reagent. One hundred $\mathrm{mL}$ of OPA reagent contained $3.18 \mathrm{~g}$ sodium tetraborate, $0.088 \mathrm{~g}$ dithiothreitol, $0.1 \mathrm{~g}$ sodium dodecyl sulphate and $0.08 \mathrm{~g}$ OPA (dissolved in $3 \mathrm{~mL}$ ethanol). Four hundreds $\mu \mathrm{L}$ of appropriately diluted sample was mixed with $3 \mathrm{~mL}$ OPA reagent, meanwhile, the duration of 
enzymatic reaction (from adding enzyme solution to substrate till adding OPA reagent) was recorded. The absorbance at $340 \mathrm{~nm}$ was read exactly after 2 min using a spectrophotometer (Cary 50 Bio, Varian). The measurement was performed in triplicate. L-Serine in deionized water (12.5-150 $\left.\mathrm{mg} \mathrm{L}^{-1}\right)$ was used as a standard. One katal of proteolytic activity was defined as the amount which breaks a mole of peptide bonds per second.

\subsection{Free amino acids}

Free amino acids were analyzed according to Troise and coworkers (2018), with some modifications. An aliquot of milk samples (0.1 mL) was spiked with d4-Lys then mixed with $0.1 \mathrm{~mL}$ of acetonitrile and centrifuged at $4{ }^{\circ} \mathrm{C}$, for $15 \mathrm{~min}$ at $21100 \times \mathrm{g}$. Samples were diluted ten times in a mixture of acetonitrile and water 50:50, then filtered by using cellulose filters (RC, $0.22 \mu \mathrm{m}$ Sartorius, Gottingen, Germany). Before injection, samples were spiked again with 13C-lysine and the chromatographic separation of amino acids was achieved by $0.1 \%$ formic acid in acetonitrile (solvent A), $0.1 \%$ formic acid in water (solvent $\mathrm{B}$ ) as LC mobile phases. The following linear gradient of solvent B (min/\%B): (0/5), (1.50/5), (8/90), (10/90) was used, the flow rate was set to $300 \mu \mathrm{L} / \mathrm{min}$ and the injection volume was $5 \mu \mathrm{L}$. Chromatographic separation of amino acids was completed through a thermostated $\left(30{ }^{\circ} \mathrm{C}\right)$ sulfobetaine modified zwitterionic HILIC (Syncronys HILIC $3.0 \mu \mathrm{m}, 50 \times 2.1 \mathrm{~mm}$, Thermo Fisher). The Accela 1250 U-HPLC system (Thermo Fisher Scientific, Bremen, Germany) was interfaced to an Exactive Orbitrap HRMS (Thermo Fisher Scientific, Bremen, Germany) and the analytes were detected through a heated electrospray interface (HESI-II) operating in positive mode. Molecular ions $[\mathrm{M}+\mathrm{H}]^{+}$listed in Table 1 were scanned in the $m / z$ range of $60-400$, while the resolving power was set to 50,000 full width at half maximum (FWHM, $m / z 200$ ) resulting in a scan time of $1 \mathrm{~s}$ with a maximum injection time of $100 \mathrm{~ms}$. The interface parameters were as follows: spray voltage $4.5 \mathrm{kV}$, capillary voltage $20.5 \mathrm{~V}$, skimmer voltage $16 \mathrm{~V}$, tube lens voltage $110 \mathrm{~V}$, capillary temperature $295{ }^{\circ} \mathrm{C}$, heater temperature $300{ }^{\circ} \mathrm{C}$, sheath gas flow 42 and auxiliary gas flow 6 arbitrary units. Calibration of the instrument and analytical performances were monitored according to previous papers from our group. The exact mass of

Table 1

Liquid chromatography high-resolution mass spectrometry (LC-HRMS) performances of reference calibration curves. RT (retention time, min); TM (theoretical mass, $[\mathrm{M}+\mathrm{H}]^{+}$); EM (experimental mass, $[\mathrm{M}+\mathrm{H}]^{+}$); error $(\mathrm{ppm})$, IS (internal standard).

\begin{tabular}{|c|c|c|c|c|c|}
\hline Type & $\begin{array}{l}\text { Amino acids } \\
{[\mathrm{M}+\mathrm{H}]^{+}}\end{array}$ & Rt (min) & TM & EM & $\begin{array}{l}\text { Error } \\
(\mathrm{ppm})\end{array}$ \\
\hline \multirow[t]{4}{*}{ Aliphatic } & Alanine & 4.48 & 90.05496 & 90.05518 & -2.44 \\
\hline & Valine & 4.47 & 118.08626 & 118.08622 & 0.34 \\
\hline & Leucine & 3.00 & 132.10191 & 132.10143 & 3.63 \\
\hline & Isoleucine & 3.23 & 132.10191 & 132.10182 & 0.68 \\
\hline \multirow[t]{8}{*}{ Aromatic } & Phenylalanine & 3.83 & 166.08626 & 166.08589 & 2.23 \\
\hline & Tryptophan & 4.13 & 205.09715 & 205.09697 & 0.88 \\
\hline & Tyrosine & 4.44 & 182.08117 & 182.08169 & -2.86 \\
\hline & Methionine & 4.19 & 150.05833 & 150.05818 & 1.00 \\
\hline & Serine & 5.02 & 106.04987 & 106.04951 & 3.39 \\
\hline & Threonine & 4.83 & 120.06552 & 120.06559 & -0.58 \\
\hline & Asparagine & 5.08 & 133.06077 & 133.06098 & -1.58 \\
\hline & Glutamine & 1.94 & 147.07642 & 147.07651 & -0.61 \\
\hline \multirow[t]{2}{*}{ Acidic } & Aspartic acid & 5.69 & 134.04478 & 134.04457 & 1.57 \\
\hline & Glutamic acid & 5.11 & 148.06043 & 148.06004 & 2.63 \\
\hline \multirow[t]{3}{*}{ Basic } & Arginine & 4.67 & 175.11895 & 175.11888 & 0.40 \\
\hline & Histidine & 4.65 & 156.07675 & 156.07677 & -0.13 \\
\hline & Lysine & 4.71 & 147.11280 & 147.11273 & 0.48 \\
\hline \multirow[t]{3}{*}{ Unique } & Proline & 4.68 & 116.07061 & 116.07071 & -0.86 \\
\hline & Glycine & 4.79 & 76.03930 & 76.03922 & 1.05 \\
\hline & Hydroxyproline & 4.99 & 132.06551 & 132.06547 & 0.30 \\
\hline \multirow[t]{2}{*}{ IS } & ${ }^{13} \mathrm{C}$-Lysine & 4.71 & 148.11616 & 148.11599 & 1.15 \\
\hline & d4-Lysine & 4.71 & 151.13791 & 151.13761 & 1.98 \\
\hline
\end{tabular}

13C-Lys $\left([\mathrm{M}+\mathrm{H}]^{+}\right.$148.11616) was used as a reference to maximize instrumental response after each injection while deuterated lysine was used to monitor recovery upon each extraction

\subsection{Volatiles organic compounds}

Analysis of the volatiles organic compounds (VOCs) was performed by SPME GC-MS according to Bottiroli, Aprea, Betta, Fogliano, \& Gasperi (2020). Five $\mathrm{mL}$ of sample were placed into $20 \mathrm{~mL}$ glass vials for gas-chromatography (Supelco, Bellefonte, PA,) and 4-methyl-2pentanone was chosen as internal standard. Volatiles compounds were extracted with a $2 \mathrm{~cm}$ DVB-Carboxen-PDMS SPME fiber at $40{ }^{\circ} \mathrm{C}$ for $60 \mathrm{~min}$. Desorption occurred at $250{ }^{\circ} \mathrm{C}$ in the injector port of a GC Clarus 500 (PerkinElmer, Norwalk, CT) interfaced with a mass detector operating in an electron ionization mode (internal ionization source: $70 \mathrm{eV}$; scan range: $m / z$ 33-300). An auto-sampling system (CTC combiPAL, CTC Analysis AG, Zwingen, Switzerland) automatically managed the procedure. Characteristics of the HP-Innowax fused-silica capillary column (Agilent Technologies, Palo Alto, CA) used for the separation are described as follow: $30 \mathrm{~m}, 0.32 \mathrm{~mm}$ inner diameter, $0.5 \mu \mathrm{m}$ film thickness. The oven temperature steps of the GC consisted in $40{ }^{\circ} \mathrm{C}$ for $3 \mathrm{~min}, 180^{\circ} \mathrm{C}$ for $6 \mathrm{~min}$ at $4{ }^{\circ} \mathrm{C} / \mathrm{min}$ and $220^{\circ} \mathrm{C}$ for $3 \mathrm{~min}$ at $3{ }^{\circ} \mathrm{C} / \mathrm{min}$. The gas carrier was helium with a flow rate set at $2 \mathrm{~mL} / \mathrm{min}$. Compound identification was achieved by match of the observed mass spectra with the ones available from the NIST-2014/Wiley 7.0 libraries. Linear retention indices (LRI) were also calculated by the analysis of a homologous series of n-alkanes C7-C30 (Supelco, Bellefonte, PA) applying the same chromatography conditions. Results of the applied methodology were semi-quantitative. The same GC methodology was also applied to estimate the initial VOCs profile of the tested LPs, which were diluted with deminarelized until a similar enzymatic concentration to the UHLMs was reached.

\subsection{Color analysis}

A colorimeter (CM-3500d, Minolta, Japan) was used to measure the color of the UHLM samples at the different stages of shelf-life. The instrument registered the light transmittance of the sample and expressed the results in the CIELAB color system. Internal calibration was performed with distilled water and an opaque material provided by the manufacturer. UHLM samples were poured in quartz cells having $1 \mathrm{~cm}$ of optical path and measurements were carried out at room temperature. Three repetition were performed for each sample.

\subsection{Sensory evaluation}

Sensory evaluation of UHLM samples was carried out by descriptive analysis, whose procedure is described elsewhere (Troise et al., 2016). A trained panel was used for the sensory evaluation of the samples. The panel was composed by professionals employed in the dairy sector with a long-standing experience on sensory evaluation of milk. Each product was evaluated twice along the shelf-life, namely at 30 and 120 days of storage. For each tasting session, 16-21 judges participated to the sensory test and were asked to describe the UHLM samples in term of the following attributes: white color, overall flavor, mouthfeel, sweetness, cooked flavor, milky flavor, stale flavor, irregular flavor. The intensity of each attribute were rated on a 9-point category scale ( 1 = attribute not detected and $9=$ attribute extremely strong). In each tasting session, samples were labelled with three-digit random numbers and a blind replicate was introduced to keep track of the panel performances. Samples were presented to the judges in a balanced order.

\subsection{Statistical analysis}

Principal Component Analysis (PCA) was performed on free amino 
acids profiles to explore spatial distribution of the UHLM samples at the different stages of shelf-life. Partial Least Square Discriminant Analysis (PLS-DA) was also employed on the same dataset to sharpen the separation between the samples and identify those variables responsible for the classification. Before applying the two mentioned statistical techniques, free amino acids profile data were log-transformed and scaled to unit variance. Differences in the VOCs profiles, sensory properties and color due to the storage time and the LP employed were investigated by analysis of the variance. When coming across a significant difference, Tukey post-hoc test was applied. Correlations among sensory and instrumental variables were investigated by Multiple Factorial Analysis (MFA). The analysis was run on the mean values of free amino acids, VOCs, color and sensory data at 30 and 120 days of shelf-life. Storage time and type of LP were supplied to the MFA as supplementary data, whereas sensory and instrumental measurements were considered as active. The number of factors to consider was chosen according to the Kaiser's criterion (eigenvalue $>1$ ), as previously done by Boris et al. (2018). Univariate correlation analysis (based on Pearson regression coefficient) was also performed in support to the MFA for a better interpretation of the linear relationships among the variables. RStudio (RStudio Team (2018). RStudio: Integrated Development for R. RStudio, Inc., Boston, MA) and STATISTICA 13.3 (StatSoft, Inc., Tulsa, OK) were used for both univariate and multivariate data analysis.

\section{Result and discussion}

\subsection{Proteolytic side activity and release of free amino acids}

The proteolytic side activity of each LP was estimated by o-phthalaldehyde (OPA) method to get insights on their initial purity. Fig. 1 illustrates the results of the analysis and pointed out a significant difference in the proteolytic activity of the commercial LPs. LP2 was characterized by the highest proteolytic activity and, as a consequence, it can be considered the least purified lactase according to the OPA method. Its level of proteolytic activity $(\mu \mathrm{Kal} / \mathrm{mL})$ was significantly higher than LP1 $(P=0.0218)$ and LP3 $(P=0.0002)$. At the same time, the proteolytic side activity of LP3 was significantly lower than LP1 $(P=0.0002)$, meaning that this enzymatic preparation was the one containing the lowest level of proteolytic side activity. The results confirmed that the lactases intended for UHLM production are available with various degree of purity in the market (Nielsen et al., 2018). Different separation methods are usually applied for their isolation

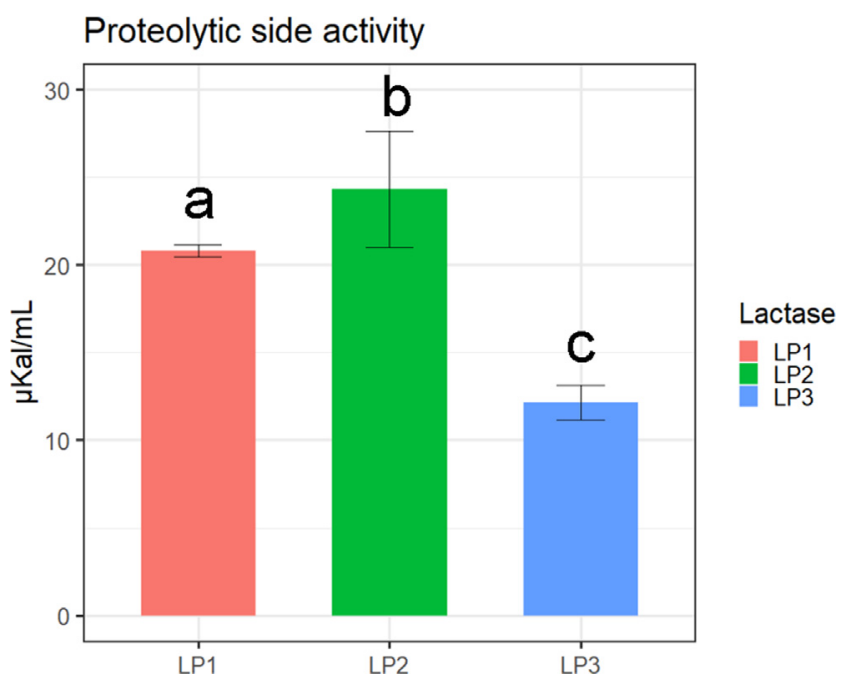

Fig. 1. Proteolytic side activity of the tested commercial LPs estimated by ophthalaldehyde (OPA) method. Nilac low-heat skim milk powder was used as substrate. from microorganisms (e.g. centrifugation and column chromatography), but apparently secondary proteases are not entirely removed (Zhao et al., 2019) and can promote proteolysis in UHLM. To investigate the ability of the "in batch" production of minimizing unwanted proteolytic activity, LC-HRMS was applied to monitor the release of free amino acids during storage. Following the HILIC zwitterionic separation, Cys was not detected whereas Ile and Leu were quantified as one single peak (Ile/Leu) because the separation of the two isomers was not achieved in milk samples, but only in calibration curve trials. Time course evolution of each amino acid (Supplementary Fig. A.1) showed that the concentration of Ile/Leu, Trp, Val, Phe, Tyr, Arg, His, Pro, Gln, ProOH, Glu and Asp was constant throughout the shelf-life of UHLM. These results confirmed that the milk produced by "in batch" system is poorly affected the proteolytic side activity of the LP, probably because these proteases are inactivated by the UHT treatment (Dekker et al., 2019; Troise et al., 2016).

Explorative Principal Component Analysis (PCA) was performed for dimension reduction to visualize possible patterns in the samples based on their free amino acids profile. A tendency of separation was shown by the bi-plot of the first two principal components (Supplementary Fig. B.1), but the best visualization of this trend was given by plotting the first (accounting for $26.1 \%$ of the explained variance) and the fifth principal components (7.3\% of the explained variance) (Fig. 2). This plot revealed that the tested LP contributed to a specific free amino acids profile in the milk and that this behavior was poorly related to the storage time. Apparently, the differences in free amino acids were registered already at the beginning of the shelf-life study, namely at 0 days of storage.

Proteolysis occurred at different extent before the UHT treatment, likely during the $25-30 \mathrm{~h}$ of incubation adopted to achieve the desired level of lactose hydrolysis. According to the "in batch" production system, lactose hydrolysis is carried out at refrigerated temperature (Harju et al., 2012), although this conditions is far from the optimal temperature of the lactase $\left(35-65{ }^{\circ} \mathrm{C}\right.$ according to Mahoney, 1997). Therefore, a holding time is necessary to complete the batch hydrolysis implying higher dosages of LP (Tossavainen \& Kallioinen, 2007). This explains the different release of free amino acids in the UHLM observed before shelf-life. The assumption is reasonable because when the lactase is not thermally inactivated, a typical feature of the "in pack" system, the action of the LP proteolytic side activity causes temporal changes in the free amino acids profile (Jansson, Jensen, Sundekilde, et al., 2014; Nielsen et al., 2017; Troise et al., 2016). Moreover, the relatively low percentage of variance explained by the PCA model may suggest that, in realistic industrial settings, the breakdown of the milk protein is limited when UHLM is produced "in batch" due to the destructive effect of the UHT treatment on the proteolytic side activity of the LP.

In order to better identify the variables responsible for the observed trends, PLS-DA was applied. This model relies on the rotation of the PCA components to maximize the separation among the groups of observation (Aprea et al., 2011). The score plot of the PLS-DA model is given in Fig. 3a. The robustness of the model was confirmed by the low balanced error rate obtained (BER $=0.03125$ ) as well as by a correct responses in prediction higher than $90 \%$ for all the cases (Table 2). Next, the impact of each amino acid on the classification was investigated by calculating the variable importance in prediction value (VIP): those higher than 1 (Fig. $3 \mathrm{~b}$ ) were considered the most relevant for explaining the separation (Aprea et al., 2011). In total, 6 out of the 18 quantified amino acids demonstrated a VIP $>1$, with Ile/Leu and ProOH registering the highest values (VIP equal to 2.41 and 1.69 respectively). Large amounts of hydroxyproline (ProOH) and proline (Pro) are present in collagen and milk protein (Wu et al., 2011), specifically hydroxyproline is not detected in milk background in free form and its concentration may arise as a consequence of protein hydrolysis or free proline hydroxylation (Abernethy \& Higgs, 2013). The fact that the levels of ProOH in the analyzed samples were 6-7 times lower than Pro confirmed the assumption. ProOH separated UHLM with LP1 from 


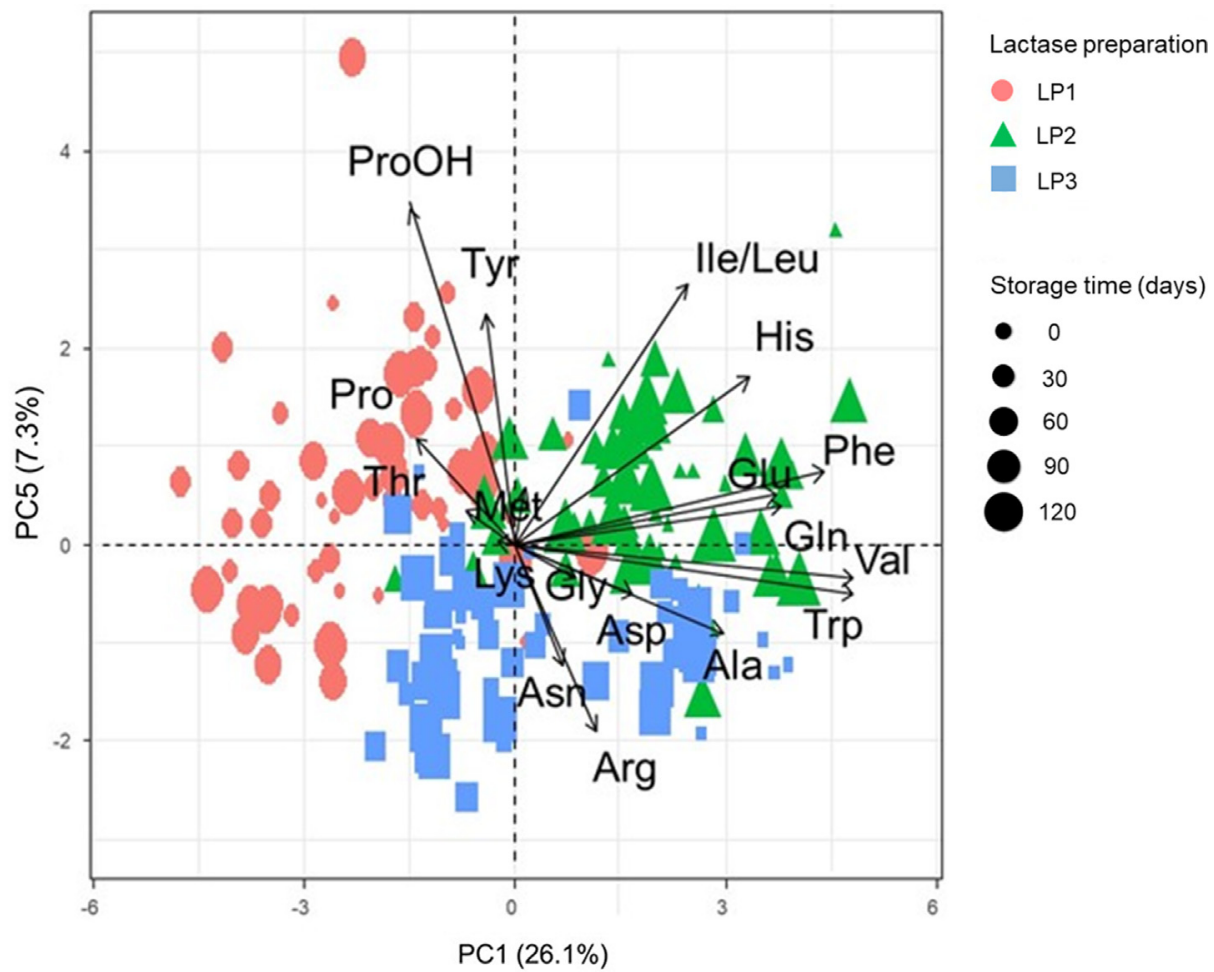

Fig. 2. Principal Component Analysis (PCA) bi-plot of the first (PC1) and the fifth (PC5) principal components performed on the free amino acids data of the UHLM samples produced by "in batch" system with LP1 (red), LP2 (green), LP3 (blue) during storage at $20^{\circ} \mathrm{C}$ for 120 days. The explained variance for each component is also reported. The proceeding of the storage time is represented by an increasing size of the dots. Black arrows indicated the corresponding weights of the loadings on the spatial distribution of the UHLM samples. (For interpretation of the references to color in this figure legend, the reader is referred to the web version of this article.)
LP2 and LP3, while Ile/Leu, Glu, Trp and Val separated the UHLM with LP2 from the rest of the samples. The same pattern was visualized by the loadings of the PCA described in Fig. 2. All together the results demonstrated higher concentration of free amino acids in UHLM containing LP2, namely the lactase characterized by the highest level of proteolytic side activity according to the OPA results (Fig. 1). Differently, milk with LP3 was the more purified lactase and it was slightly affected by the release of free amino acids. According to Jansson, Jensen, Sundekilde, et al. (2014) and Nielsen et al. (2018), proteolysis in UHLM targets the intact $\beta$-casein $(\beta-\mathrm{CN})$ and $\alpha_{\mathrm{s} 1}$-casein $\left(\alpha_{\mathrm{s} 1}-\mathrm{CN}\right)$, denoting a specificity of the secondary proteases to particular protein structures. Nielsen et al. (2018) in particular, reported that degradation of $\beta-C N$ and $\alpha_{s 1}-C N$ vary depending on the LP purity and is related to a mutual presence of exopeptidases and endopeptidases in the preparations, which release C-terminal amino acids residues (Ile-Ile-Val, Ile-Val and Trp) in the milk during storage. Our results indicated higher levels of free Ile/Leu, Val and Trp in the UHLM produced with LP2. Therefore, we might consider the release of free amino acids in UHLM as an interplay between the different degree of proteolytic side activity of the $\mathrm{LP}$ and the specificity of these proteases towards particular sites of $\beta-\mathrm{CN}$ and $\alpha_{s 1}-\mathrm{CN}$. On the other hand, we cannot exclude that also other types of protein are degraded by the proteolytic side lactase activity of LP.
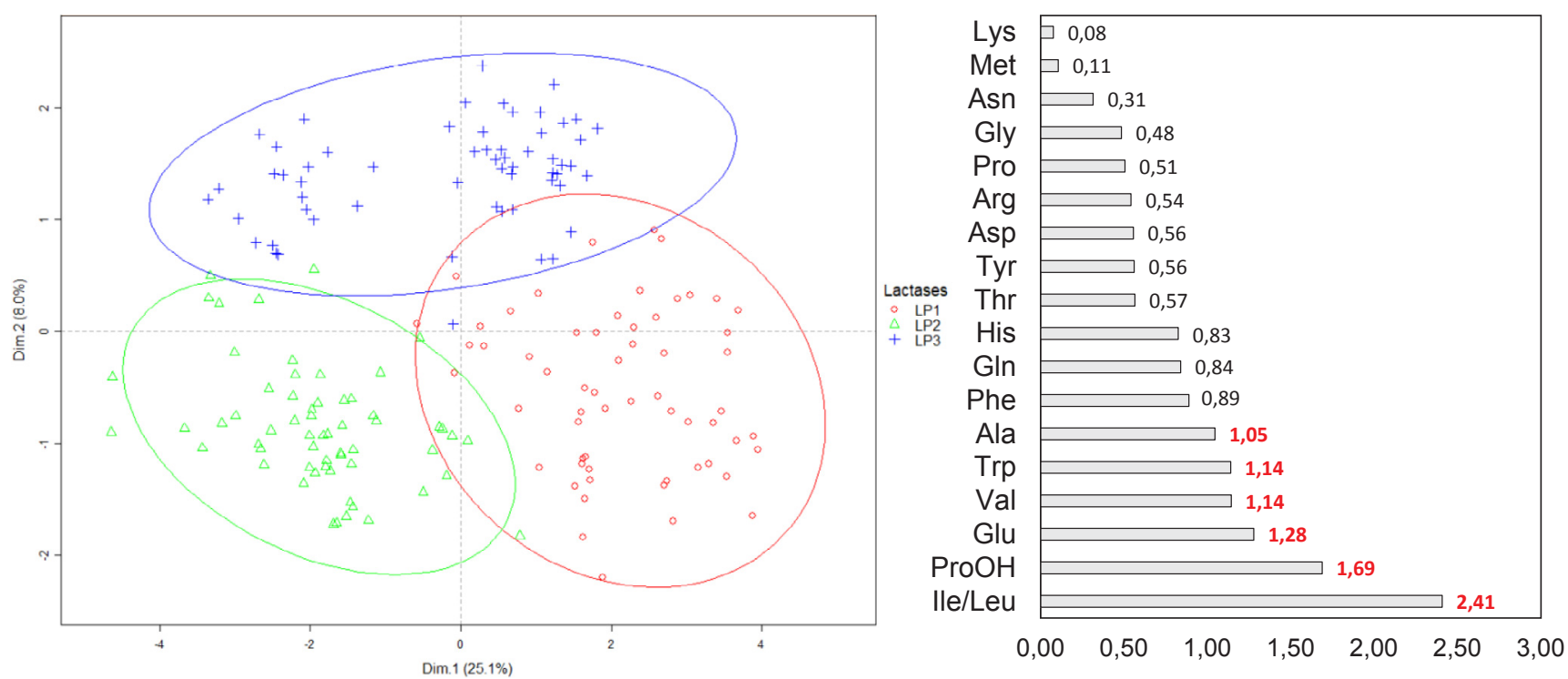

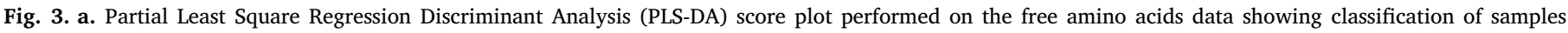

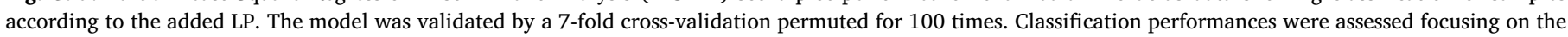

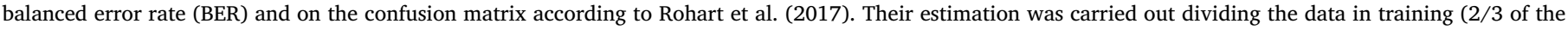

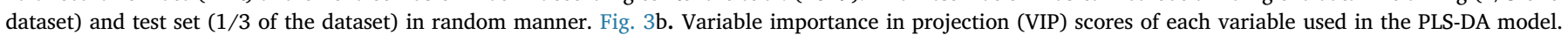


Table 2

Confusion matrix generated by the PLS-DA model for the different UHLM produced by "in batch" system using three different LP. The last column reports the percentage of correct classifications based on the maximum prediction distance. Training set $(2 / 3$ of the dataset) and test set $(1 / 3$ of the dataset) were generated in random manner to compute the model.

\begin{tabular}{llllll}
\hline $\begin{array}{l}\text { Lactase } \\
\text { preparations }\end{array}$ & $\begin{array}{l}\text { Predicted as } \\
\text { LP1 }\end{array}$ & $\begin{array}{l}\text { Predicted as } \\
\text { LP2 }\end{array}$ & $\begin{array}{l}\text { Predicted as } \\
\text { LP3 }\end{array}$ & Total & \% correct \\
\hline LP1 & 20 & 0 & 0 & 20 & $100 \%$ \\
LP2 & 0 & 21 & 0 & 21 & $100 \%$ \\
LP3 & 1 & 2 & 29 & 32 & $91 \%$ \\
\hline
\end{tabular}

Table 3

List of the volatile compounds (VOCs) identified and quantified in the headspace of the UHLM produced by "in batch" system using the three different commercial LP during storage at $20{ }^{\circ} \mathrm{C}$ for 120 days by SPME GC-MS. The concentrations expressed as $\mu \mathrm{g} / \mathrm{L}$ of internal standard (4-methyl-2-pentanone) for each VOCs analyzed in UHLM samples are available in the Appendix (Supplementary Table A.1).

\begin{tabular}{llll}
\hline Compound name $^{\mathrm{a}}$ & $\mathrm{RT}^{\mathrm{b}}$ & LRI $^{\mathrm{c}}$ & Reference LRI $^{\mathrm{d}}$ \\
\hline 2-butanone & 2.66 & 909 & $907 \pm 11$ \\
2-methylbutanal & 2.83 & 918 & $914 \pm 8$ \\
2-pentanone & 4.01 & 985 & $981 \pm 11$ \\
Toluene & 5.49 & 1051 & $1042 \pm 11$ \\
Hexanal & 6.62 & 1099 & $1083 \pm 8$ \\
Ethyll-benzene & 7.90 & 1137 & $1129 \pm 8$ \\
2-heptanone & 9.70 & 1191 & $1182 \pm 8$ \\
2-nonanone & 16.61 & 1395 & $1390 \pm 7$ \\
Nonanal & 16.77 & 1400 & $1391 \pm 8$ \\
Benzaldehyde & 20.92 & 1531 & $1520 \pm 14$ \\
1-octanol & 22.07 & 1576 & $1557 \pm 8$ \\
2-undecanone & 23.16 & 1605 & $1598 \pm 6$ \\
$\gamma$-butyrolactone & 24.07 & 1636 & $1632 \pm 15$ \\
Aceto-phenone & 24.74 & 1660 & $1647 \pm 13$ \\
2-tridecanone & 29.16 & 1818 & $1809 \pm 6$ \\
Hexanoic acid & 31.06 & 1890 & $1846 \pm 12$ \\
Dimethyl-sulfone & 31.56 & 1909 & $1903 \pm 9$ \\
p-cresol & 36.18 & 2095 & $2080 \pm 12$ \\
m-cresol & 36.36 & 2103 & $2091 \pm 18$ \\
Octanoic acid & 36.40 & 2104 & $2060 \pm 15$ \\
$\delta$-decalactone & 38.62 & 2198 & $2194 \pm 15$ \\
Decanoic acid & 42.25 & 2295 & $2267 \pm 14$ \\
\hline a & & & \\
\hline
\end{tabular}

a Compound identification by match with the NIST-2014/Wiley 7.0 libraries.

b Retention time (min).

c Linear retention index.

d Reference linear retention index reported in the NIST-2014 library.

Overall, the results demonstrated that the release of free amino acids in UHLM produced by "in batch" depends on the initial proteolytic side activity of the LP, at least until the UHT treatment is applied.

\subsection{Volatiles organic compounds profile}

Table 3 summarizes the VOCs measured by HS SPME GC-MS. A total of 22 VOCs matched the spectra of the NIST/Wiley libraries, with several compounds already reported in other published articles on both regular and hydrolyzed-lactose UHT milk (Jansson, Jensen, Eggers, et al., 2014c; Jeon, Thomas, \& Reineccius, 1978; Rysstad, Ebbesen, \& Eggestad, 1998). The calculated LRIs for each VOC were similar to the one previously reported by our group (Bottiroli, Aprea, et al., 2020; Bottiroli, Pedrotti, et al., 2020; Bovolenta, et al.,2014), as well as to the ones avaiable from the NIST library.

Statistically significant differences were found in the VOCs profile of the UHLM produced with the different LPs. Fig. 4 shows that 2-methylbutanal (Fig. 4a) and benzaldehyde (Fig. 4c) exhibited different temporal evolution depending on the LP employed. Both volatile compounds are mainly formed in UHT milk from the intermediate stages of MR through Strecker degradation (van Boekel, 2006). The reaction arises when the amino acids react either with $\alpha$-dicarbonyl compounds or Amadori products by deamination and decarboxylation (Cremer, Vollenbroeker, \& Eichner, 2000; Hofmann \& Schieberle, 2000).

The aldehyde 2-methylbutanal is formed via the degradation of $\alpha$ amino acids initiated by carbonyl compounds and, alternatively, by branching-off of Ile/Leu Amadori compounds (Cremer et al., 2000; Jansson, Clausen, et al., 2014). Benzaldehyde is also formed via Strecker degradation of Phe and subsequent oxidation of phenylacetaldeyde (Fong \& Yaylayan, 2008). Overall, specific trends in the release of Strecker aldehydes were shown in relation to the initial purity of the tested LP. The formation rate of 2-methybutanal was higher in the UHLM containing LP1 and LP2 compared to LP3. The highest concentration of this compound was reached at the end of the shelf-life study by the UHLM with LP2. Interestingly, the release of 2-methylbutanal was proportional to the initial higher levels of free Ile/Leu in this product as well as to the lower purity of LP2. Similarly, benzaldehyde remarkably increased in UHLM produced with LP1 and the concentration was significantly higher after 120 days of storage compared to the UHLM with LP3. In this case, a match with the trend of Phe was not found, as the initial concentration of the free amino acid in the UHLMs did not differ based on the tested LP. In combination with the free amino acids profiles, the measurement of 2-methylbutanal and benzaldehyde are therefore important data to understand the pathway of off-flavor formation in UHLM depending on the LP purity. The free amino acids released by the proteolytic side activity of LP fuel the ongoing MR and, together with the reducing sugar from lactose hydrolysis, result in the formation of flavor-active Strecker aldehydes responsible for changes in the UHLM flavor (Nielsen et al., 2017).

Mitigation strategies for undesired flavor development have been recently outlined by Jansson and colleagues (2019): addition of green tea extract (GTE) favored a reduction in the concentration of Strecker aldehydes in UHLM, with concomitant decrease in the mushroom flavor of the product. According to Nielsen et al. (2017), Strecker aldehydes contribute to the development of stale flavor in UHLM during storage.

Strecker-derived volatiles compounds can therefore be considered the bridge to correlate the initial level of proteolytic side activity of the LP with the proceeding of MR and the off-flavor development in UHLM. In our case, the combined measurements of VOCs and free amino acids demonstrated that, despite the thermal inactivation of the LP during "in batch" production, MR proceeded in UHLM at different extent based on the LP employed.

Besides the proteolytic activity, the arylsulfatase activity coming from the LP may confer "cowshed-like" off-flavor to the milk during storage (Stressler et al., 2018). This is related to the formation of pcresol from the sulphonated-cresol naturally present in milk (Dekker et al., 2019). In our study, p-cresol was detected but its concentration did not differ significantly in the UHLMs based on the LP and was constant throughout the storage, indicating a poor contribution of the arylsulfatase activity to the final milk flavor.

Fig. 4 shows the trends over time of other VOCs highlighting those compounds that increased significantly during shelf-life, such as 2pentanone (Fig. 4b). Some other methyl-ketones followed a similar trend but the batch-to-batch milk variability hindered the possibility of spotting significant variations. Methyl-ketones are thermally-induced compounds in milk. Their increase upon UHT processing is broadly discussed in literature, as the class is correlated to the severity of the heat treatment applied (Contarini \& Povolo, 2002; Contarini, Povolo, Leardi, \& Toppino, 1997; Valero, Villamiel, Miralles, Sanz, \& MartínezCastro, 2001; Vazquez-Landaverde, Velazquez, Torres, \& Qian, 2005).

In contrast with the increase in methyl-ketones, a decrease in lactones (Fig. 4e, Fig. 4f) was observed during storage. Nevertheless, the trends highlighted by methyl-ketones and lactones are typical of UHT milk aging and did not end up in a differentiation of the UHLM based on the LP. The data of 1-octanol in UHLM (Fig. 4d) were particularly interesting: this compound was detected only in the UHLM produced with 

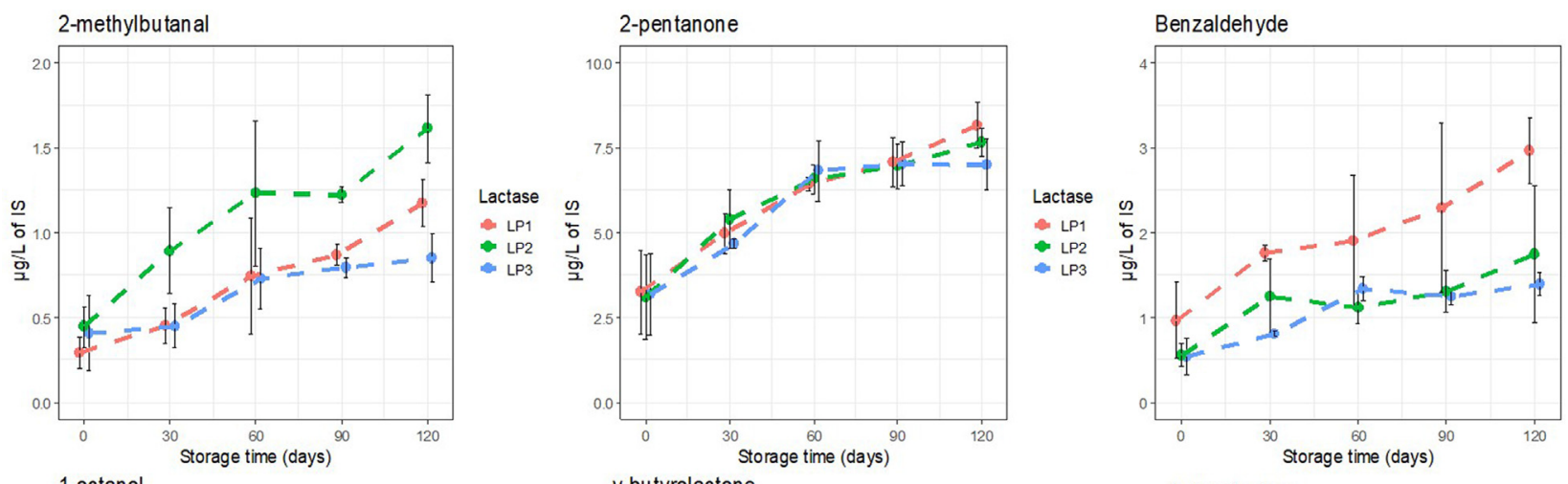

Lactase

- LP1

$*$ LP2
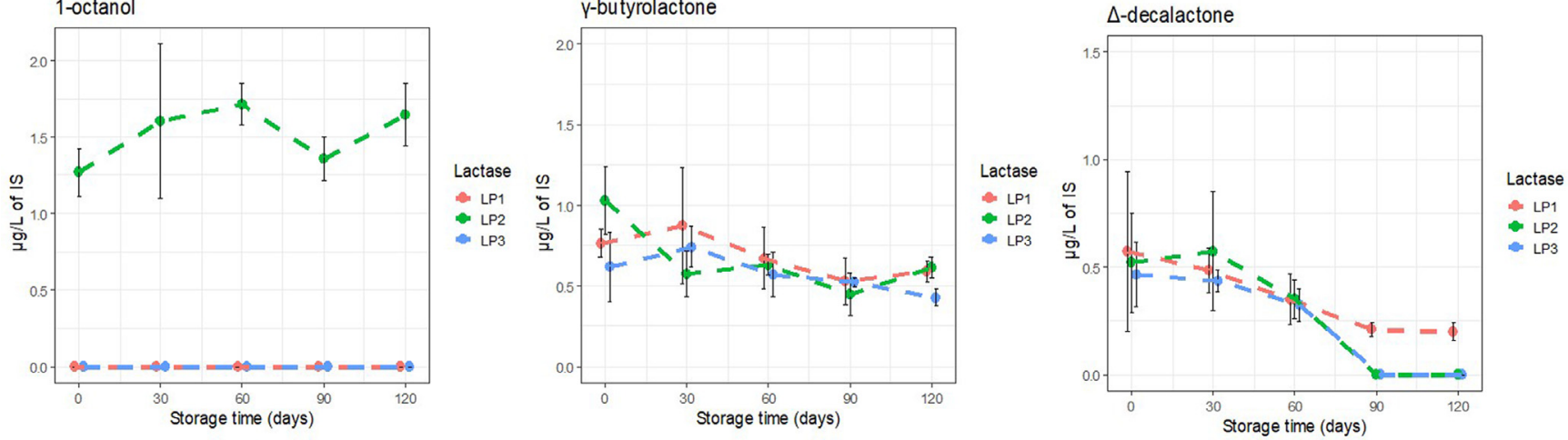

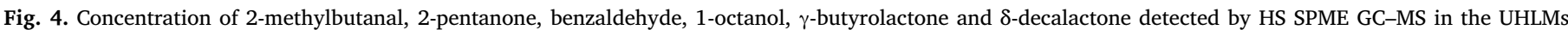
produced with LP1, LP2, LP3 during storage at $20{ }^{\circ} \mathrm{C}$ for 120 days. The data are the mean values of the three replicates of production (n $=3$ ).
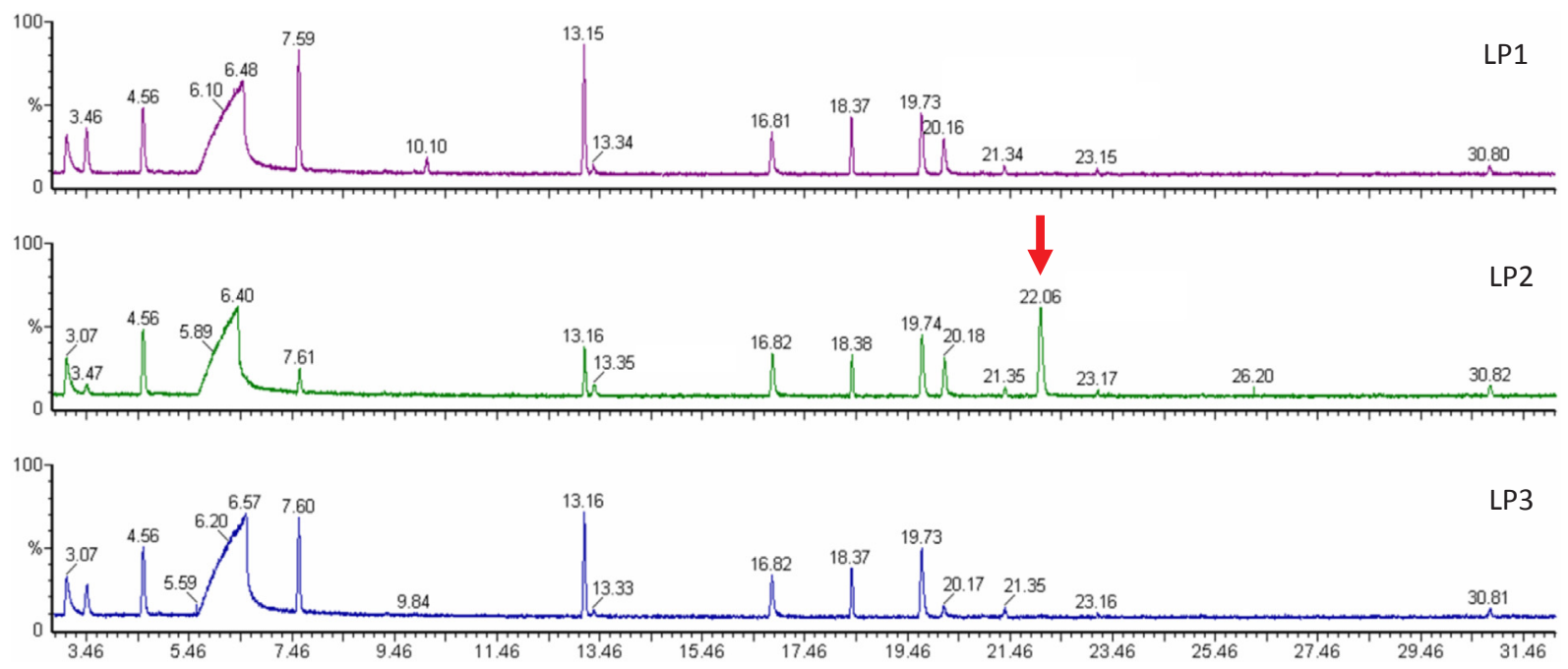

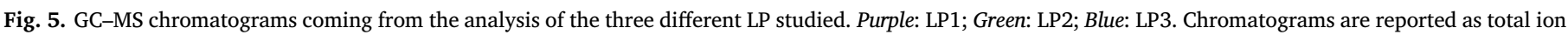

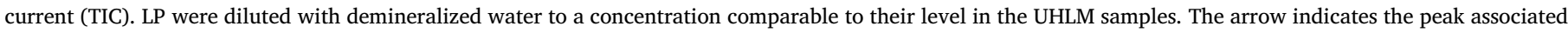
with 1-octanol (RT: 22.06). (For interpretation of the references to color in this figure legend, the reader is referred to the web version of this article.)

LP2 and remained constant throughout its shelf-life. Literature lacks of information regarding detection of 1-octanol in milk. Thus, it was reasonable to measure the volatile profiles of the three LP as such (Fig. 5) in order to verify how 1-octanol ended up in the UHLM with LP2. As expected, the peak of 1-octanol (RT: 22.06) was detected only in LP2. Thus, the higher level of proteolytic side activity was not the only factor differentiating LP2 from the other tested lactases. This latter result indicated that the initial VOCs profile of the LP may be an additional parameter for further investigation of the differences among UHLM produced with different lactase. To the best of our knowledge, this was the first time this aspect was taken into consideration.

\subsection{Color, sensory changes and correlation with small molecules analysis}

The changes in the color of the analyzed UHLM are reported in the Appendix (Supplementary Fig. C.1.). The color of the milk did not differ as function of the LP employed for production. $L^{*}$ (black: $L^{*}=0$ and white: $L^{*}=100$ ) and $b^{*}$ (yellow-blue: negative $b^{*}=$ blueness and positive $\mathrm{b}^{*}=$ yellowness) remained constant, while $\mathrm{a}^{*}$ (red-green: negative $\mathrm{a}^{*}=$ greenness and positive $\mathrm{a}^{*}=$ redness) increased significantly during storage. This results are in line with a recent study published by Jansson et al. (2019). The increase in red color denotes non-enzymatic browning undergoing in the milk during storage (Bosch, Alegría, Farré, \& Clemente, 2007). 
Sensory profiling of UHLMs was determined at 30 and 120 days of storage at $20{ }^{\circ} \mathrm{C}$. UHLMs were not perceived as different based on the tested LP. Furthermore, descriptors associated with a negative impact on the milk sensory properties (cooked flavor, stale flavor and irregular flavor) did not registered a significant increase during the shelf-life. Thus, all the milk samples did not develop significant defects during storage, although the positive attributes white color and milky flavor significantly decreased after prolonged shelf-life.

The absence of differences among the sensory profile of UHLM produced with the different lactase preparations is an important result at industrial level, because the retail price of LP is related to the relative amount of proteolytic side activity present in the preparation, with more purified lactases costing the most (Mittal, Newell, Hourigan, \& Zadow, 1991). Our results suggested that, because the quality of "in batch" UHLM is poorly correlated to the initial LP purity, production costs may be lowered by using less purified lactases. Indications on this aspect are however limited by the number of LPs we tested, so a higher number of commercial options should be evaluated in the future to validate the hypothesis.

Sensory attributes and analytes were then correlated by Multiple Factorial Analysis (MFA) to explore associations among the observations. Fig. 6 illustrates the relative loading plot of the MFA analysis that coherently interpreted the sensory and instrumental data (RVs > 0.69). Three factors, namely Dim1 (24.78\%), Dim2 (12.75\%) and Dim3 (12.51\%), were considered significant and explained $50.04 \%$ of the total variance. Significant contribution to Dim1 was given by the sensory $(29.77 \%)$, color $(29.58 \%)$ and VOCs $(26.48 \%)$ data, whereas only color (38.22\%) and VOCs (32.42\%) had a relevant impact on Dim2. Interestingly, free amino acids was the group of variables providing the highest contribution to Dim3 (64.25\%). The release of free amino acids in UHLM, which we associated to an effect of the tested LP, was confirmed as a separated phenomenon from the trends exhibited by the other groups of variables, which we associated to an effect of the storage time. Because the trained panel did not recognized any effects of the different LPs on the sensory quality of UHLM, it was reasonable to use the combination of Dim1 and Dim2 to describe the correlations of the sensory properties with the instrumental parameters. Dim1 reflected the effects of the storage time on the sensory and chemical properties of UHLM. White color, milky flavor and mouthfeel gave strong negative contribution to the dimension and were inversely correlated to stale flavor, some VOCs and the $\mathrm{a}^{*}$ and $\mathrm{b}^{*}$ color parameters. Looking at the Pearson correlation coefficients (r), white color registered the highest negative relationship with $a^{*}(r=-0.83)$, which was at the same time positively correlated to methyl ketones ( $r>0.65$ for 2-butanone, 2-pentanone, 2-nonanone and 2-undecanone) and, at lower degree, to 2-methylbutanal $(r=0.49)$ and benzaldehyde $(r=0.55)$. MR underlies the results: the reaction is facilitated in UHLM due to the higher reactivity of the formed glucose and galactose (Naranjo, Gonzales, Leiva, \& Malec, 2013), Strecker aldehydes are formed at the intermediate stages (van Boekel, 2006) and its proceeding eventually ends up in the formation of brown pigments and polymers as melanoidins (van Boekel, 2001). Formation of brown pigments, already estimated by Sunds and coworkers (2018) by the CIELAB system, explained the significant increase of $\mathrm{a}^{*}\left(+\mathrm{a}^{*}=\right.$ redness, $-\mathrm{a}^{*}=$ greenness $)$ registered in our experiment. The Strecker aldehydes themselves could also have contributed to such change in color, as a result of condensation (Morales \& van Boekel, 1998), even if the major contribution of Strecker degradation is given to the off-flavor. Indeed, stale flavor, one of the most encountered sensory defects in UHT milk, correlated positively with cooked flavor $(r=0.55)$ and negatively with milky flavor $(r=-0.60)$ and mouthfeel $(r=-0.52)$, indicating its increase during storage at the expenses of those sensory attributes highly desirable in milk. Stale flavor is associated to an increase in methyl ketones and aldehydes during the shelf-life for both UHLM and regular UHT milk (Jensen et al., 2015; Perkins, Elliott, D’Arcy, \& Deeth, 2005). In our study, positive Pearson coefficients were found between stale flavor and 2-butanone $(r=0.48)$, hexanoic acid $(r=0.57)$ and octanoic acid $(r=0.49)$. While 2-butanone was already pointed out as good predictor of the flavor in UHLM (Jensen et al., 2015), the correlation with the organic acids indicated that the sensory attribute was considered by the panel probably also as "rancid" and/or "oxidized". Overall, the MFA unveiled the relationship among sensory and instrumental observations in UHLM produced by "in batch" technology. The model gave clear insights on the impact that LP and storage time

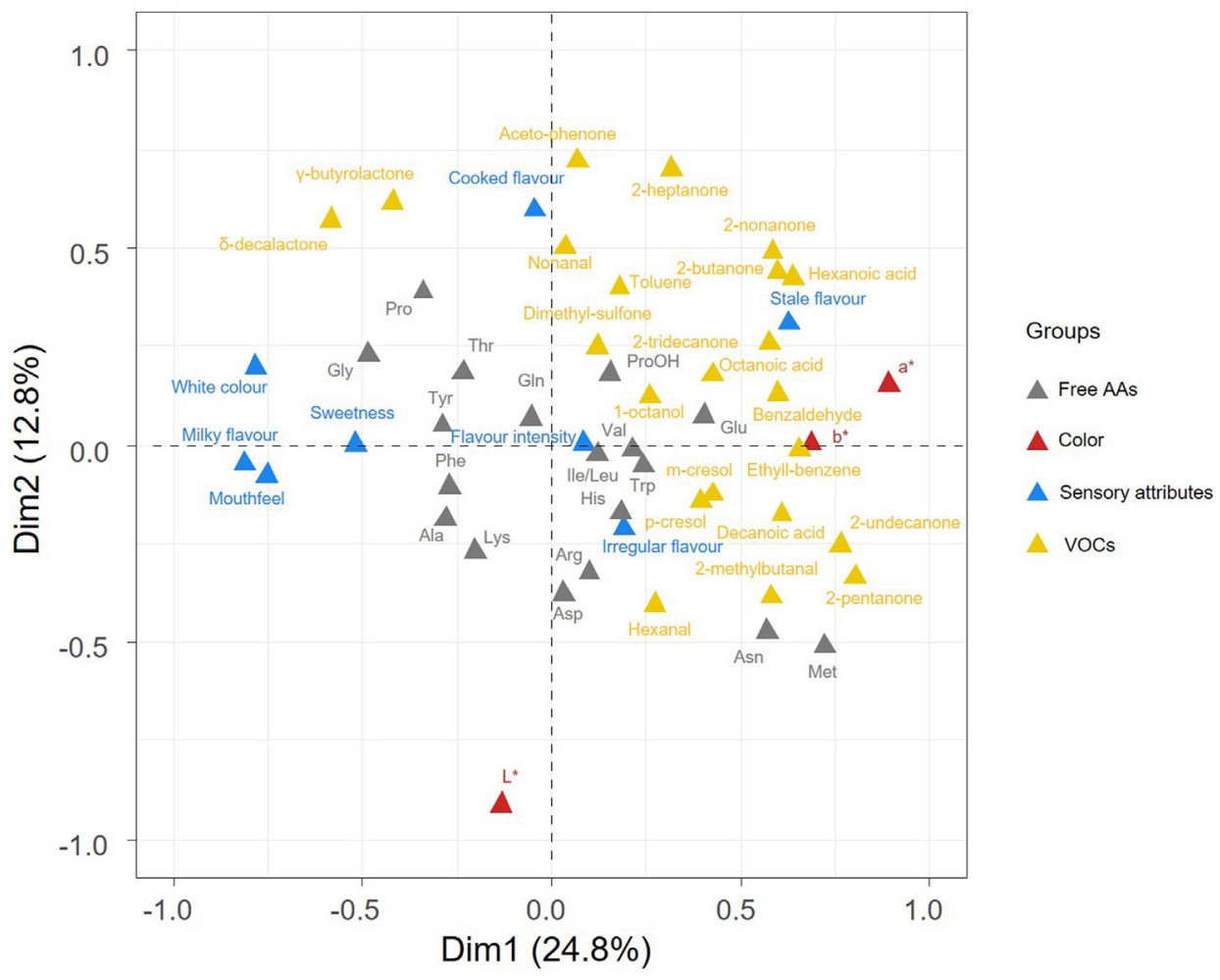

Fig. 6. Multiple factor analysis (MFA) loading plot of the quantitative variable projected on Dim 1 and Dim 2 (24.8\% and $12.8 \%$ of the total variance respectively). The analysis was performed on the mean values of the free amino acids (grey), VOCs (yellow), color (red) and sensory (blue) data extrapolated from the analysis of the UHLM samples produced with LP1, LP2 and LP3 at 30 and 120 days of shelf-life. (For interpretation of the references to color in this figure legend, the reader is referred to the web version of this article.) 
provided to the UHLM characteristics, emphasizing the role of the latter in the definition of the final product quality.

\section{Conclusion}

Commercial LPs can have different degrees of proteolytic activity. Our study provided evidence about the importance of choosing the proper lactase preparation in combination with the production process in order to produce high quality UHLM. Specifically, we demonstrated that during "in batch" production, the lactase purity does not play a crucial role, as most of the proteolytic activity is inactivated by the thermal treatment. However, the pool of free amino acids produced during the "in batch" hydrolysis is a reservoir of reactive molecules which allow the formation of volatiles during shelf-life, at different extent depending on the purity of the LP. This did not end up in a differentiation of the milk color and sensory properties. The increased diffusion of UHLM in Asia is calling the manufacturing of products with a longer shelf-life. Currently the shelf-life of UHLM is limited: understanding the mechanisms of milk aging is the prerequisite to develop strategies prolonging it up to 9-12 months, as for conventional UHT milk.

\section{CRediT authorship contribution statement}

Riccardo Bottiroli: Investigation, Formal analysis, Writing - original draft, Visualization. Antonio Dario Troise: Writing - review \& editing. Eugenio Aprea: Conceptualization, Writing - review \& editing, Supervision. Vincenzo Fogliano: Conceptualization, Funding acquisition, Resources, Writing - review \& editing, Supervision. Paola Vitaglione: Resources, Funding acquisition, Writing - review \& editing, Supervision. Flavia Gasperi: Conceptualization, Resources, Funding acquisition, Writing - review \& editing, Supervision.

\section{Declaration of Competing Interest}

The authors declared that there is no conflict of interest.

\section{Acknowledgements}

The present study was financially supported by Wageningen University, Edmund Mach Foundation, and University Federico II of Naples as part of the Ph.D. project of Riccardo Bottiroli. The authors greatly thank Chunyue Zhang and Emanuela Betta for the technical support. A special thank also to all people involved in the sensory assessment.

\section{Appendix A. Supplementary material}

Supplementary data to this article can be found online at https:// doi.org/10.1016/j.foodres.2020.109552.

\section{References}

Abernethy, G., \& Higgs, K. (2013). Rapid detection of economic adulterants in fresh milk by liquid chromatography-tandem mass spectrometry. Journal of Chromatography A, 1288, 10-20. https://doi.org/10.1016/j.chroma.2013.02.022.

Aprea, E., Gika, H., Carlin, S., Theodoridis, G., Vrhovsek, U., \& Mattivi, F. (2011). Metabolite profiling on apple volatile content based on solid phase microextraction and gas-chromatography time of flight mass spectrometry. Journal of Chromatography A, 1218(28), 4517-4524. https://doi.org/10.1016/j.chroma.2011.05.019.

Boris, S., Martin, K., Matej, P., Anna, R., Jana, M., Bohuslava, T., \& Eva, D. (2018). Application of multiple factor analysis for the descriptive sensory evaluation and instrumental measurements of bryndza cheese as affected by vacuum packaging. International Journal of Food Properties, 21(1), 1508-1522. https://doi.org/10.1080/ 10942912.2018.1494194.

Bosch, L., Alegría, A., Farré, R., \& Clemente, G. (2007). Fluorescence and color as markers for the Maillard reaction in milk-cereal based infant foods during storage. Food Chemistry, 105(3), 1135-1143. https://doi.org/10.1016/j.foodchem.2007.02.016. Bottiroli, R., Aprea, E., Betta, E., Fogliano, V., \& Gasperi, F. (2020). Application of headspace solid-phase micro-extraction gas chromatography for the assessment of the volatiles profiles of ultra-high temperature hydrolysed-lactose milk during production and storage. International Dairy Journal, 104715. https://doi.org/10.1016/j. idairyj.2020.104715.

Bottiroli, R., Pedrotti, M., Aprea, E., Biasioli, F., Fogliano, V., \& Gasperi, F. (2020). Application of PTR-TOF-MS for the quality assessment of lactose-free milk : Effect of storage time and employment of different lactase preparations. Journal of Mass Spectrometry, February, 1-9. https://doi.org/10.1002/jms.4505.

Bovolenta, S., Romanzin, A., Corazzin, M., Spanghero, M., Aprea, E., Gasperi, F., \& Piasentier, E. (2014). Volatile compounds and sensory properties of Montasio cheese made from the milk of Simmental cows grazing on alpine pastures. Journal of Dairy Science, 97(12), 7373-7385. https://doi.org/10.3168/jds.2014-8396.

Contarini, G., \& Povolo, M. (2002). Volatile fraction of milk: Comparison between, purge and trap and solid phase microextraction techniques. Journal of Agricultural and Food Chemistry, 50(25), 7350-7355. https://doi.org/10.1021/jf025713a.

Contarini, G., Povolo, M., Leardi, R., \& Toppino, P. M. (1997). Influence of Heat Treatment on the Volatile Compounds of Milk. Retrieved from. https://pubs.acs.org/ sharingguidelines.

Cremer, D. R., Vollenbroeker, M., \& Eichner, K. (2000). Investigation of the formation of Strecker aldehydes from the reaction of Amadori rearrangement products with ofamino acids in low moisture model systems. European Food Research and Technology, 211(6), 400-403. https://doi.org/10.1007/s002170000196.

Dekker, P. J. T., Koenders, D., \& Bruins, M. J. (2019). Lactose-Free Dairy Products: Market Developments, Production. Nutrition and Health Benefits. Nutrients, 11(3), 551. https://doi.org/10.3390/nu11030551.

Deng, Y., Misselwitz, B., Dai, N., \& Fox, M. (2015). Lactose intolerance in adults: Biological mechanism and dietary management. Nutrients, 7(9), 8020-8035. https:// doi.org/10.3390/nu7095380.

Fong, L. C., \& Yaylayan, V. A. (2008). Model studies on the oxygen-induced formation of benzaldehyde from phenylacetaldehyde using pyrolysis GC-MS and FTIR. Journal of Agricultural and Food Chemistry, 56(22), 10697-10704. https://doi.org/10.1021/ jf8022468.

Fuller, F., Huang, J., Ma, H., \& Rozelle, S. (2006). Got milk? The rapid rise of China's dairy sector and its future prospects. Food Policy, 31(3 SPEC. ISS.), 201-215. https://doi.org/ 10.1016/j.foodpol.2006.03.002.

Harju, M., Kallioinen, H., \& Tossavainen, O. (2012). February). Lactose hydrolysis and other conversions in dairy products: Technological aspects. International Dairy Journal, 22, 104-109. https://doi.org/10.1016/j.idairyj.2011.09.011.

Hofmann, T., \& Schieberle, P. (2000). Formation of aroma-active Strecker-aldehydes by a direct oxidative degradation of Amadori compounds. Journal of Agricultural and Food Chemistry, 48(9), 4301-4305. https://doi.org/10.1021/jf000076e.

Itan, Y., Jones, B. L., Ingram, C. J., Swallow, D. M., \& Thomas, M. G. (2010). A worldwide correlation of lactase persistence phenotype and genotypes. Retrieved from. http:// www.biomedcentral.com/1471-2148/10/36.

Jansson, T. (2014). Chemical changes and off-flavor development in lactose- hydrolyzed UHT milk during storage. Aarhus University, Department of Food Science1-192.

Jansson, T., Clausen, M. R., Sundekilde, U. K., Eggers, N., Nyegaard, S., Larsen, L. B., \& Bertram, H. C. (2014). Lactose-hydrolyzed milk is more prone to chemical changes during storage than conventional ultra-high-temperature (UHT) milk. Journal of Agricultural and Food Chemistry, 62(31), 7886-7896. https://doi.org/10.1021/ jf501671z.

Jansson, T., Jensen, S., Eggers, N., Clausen, M. R., Larsen, L. B., Ray, C., \& Bertram, H. C. (2014). Volatile component profiles of conventional and lactose-hydrolyzed UHT milk - A dynamic headspace gas chromatography-mass spectrometry study. Dairy Science and Technology, 94(4), 311-325. https://doi.org/10.1007/s13594-0140164-7.

Jansson, T., Jensen, H. B., Sundekilde, U. K., Clausen, M. R., Eggers, N., Larsen, L. B., \& Bertram, H. C. (2014). Chemical and proteolysis-derived changes during long-term storage of lactose-hydrolyzed ultrahigh-temperature (UHT) milk. Journal of Agricultural and Food Chemistry, 62(46), 11270-11278. https://doi.org/10.1021/ jf504104q.

Jansson, T., Waehrens, S. S., Rauh, V., Danielsen, B. P., Sørensen, J., Bredie, W. L. P., \& Lund, M. N. (2019). Effect of green tea catechins on physical stability and sensory quality of lactose-reduced UHT milk during storage for one year. International Dairy Journal, 95, 25-34. https://doi.org/10.1016/j.idairyj.2019.03.007.

Jelen, P., \& Tossavainen, O. (2003). Low lactose and lactose-free milk and dairy products Prospects, technologies and applications. Australian Journal of Dairy Technology, 58(2), 161-165.

Jensen, S., Jansson, T., Eggers, N., Clausen, M. R., Larsen, L. B., Jensen, H. B., \& Bertram, H. C. (2015). Storage-induced changes in the sensory characteristics and volatiles of conventional and lactose-hydrolyzed UHT processed milk. European Food Research and Technology, 240(6), 1247-1257. https://doi.org/10.1007/s00217-015-2427-9.

Jeon, I. J., Thomas, E. L., \& Reineccius, G. A. (1978). Production of volatile flavor compounds in ultrahigh-temperature processed milk during aseptic storage. Journal of Agricultural and Food Chemistry, 26(5), 1183-1188. https://doi.org/10.1021/ jf60219a039.

Mahoney, R. R. (1997). Lactose: Enzymatic Modification. In P. F. Fox (Ed.), Advanced Dairy Chemistry Volume 3: Lactose, water, salts and vitamins (pp. 77-125). https:// doi.org/10.1007/978-1-4757-4409-5_3

Mendoza, M. R., Olano, A., \& Villamiel, M. (2005). Chemical indicators of heat treatment in fortified and special milks. Journal of Agricultural and Food Chemistry, 53(8), 2995-2999. https://doi.org/10.1021/jf0404061.

Mittal, S., Newell, G., Hourigan, J., \& Zadow, J. (1991). The effect of protease contamination in lactase on the flavour of lactose-hydrolyzed milks. Australian Journal of Dairy Technology, 46(1), 46-47.

Morales, F. J., \& Van Boekel, M. A. J. S. (1998). A study on advanced Maillard reaction in 
heated casein/sugar solutions: Colour formation. International Dairy Journal, 8(10-11), 907-915. https://doi.org/10.1016/S0958-6946(99)00014-X.

Naranjo, G. B., Gonzales, A. S. P., Leiva, G. E., \& Malec, L. S. (2013). The kinetics of Maillard reaction in lactose-hydrolysed milk powder and related systems containing carbohydrate mixtures. Food Chemistry, 141(4), 3790-3795. https://doi.org/10. 1016/j.foodchem.2013.06.093.

Nielsen, S. D., Jansson, T., Le, T. T., Jensen, S., Eggers, N., Rauh, V., \& Larsen, L. B. (2017). Correlation between sensory properties and peptides derived from hydrolysed-lactose UHT milk during storage. International Dairy Journal, 68, 23-31. https:// doi.org/10.1016/j.idairyj.2016.12.013.

Nielsen, S. D., Zhao, D., Le, T. T., Rauh, V., Sørensen, J., Andersen, H. J., \& Larsen, L. B. (2018). Proteolytic side-activity of lactase preparations. International Dairy Journal, 78, 159-168. https://doi.org/10.1016/j.idairyj.2017.12.001.

Perkins, M. L., Elliott, A. J., D’Arcy, B. R., \& Deeth, H. C. (2005). Stale flavour volatiles in Australian commercial UHT milk during storage. Australian Journal of Dairy Technology, 60(3), 231-237.

Rysstad, G., Ebbesen, A., \& Eggestad, J. (2009). Sensory and chemical quality of UHTmilk stored in paperboard cartons with different oxygen and light barriers. Food Additives \& Contaminants, 15(1), 112-122.

Sahin, S., Hamamci, H., \& Garayev, S. (2016). Rheological properties of lactose-free dairy desserts. Food Science and Technology International, 22(7), 609-620. https://doi.org/ $10.1177 / 1082013216636262$.

Stressler, T., Reichenberger, K., Glück, C., Leptihn, S., Pfannstiel, J., Swietalski, P., \& Fischer, L. (2018). A natural variant of arylsulfatase from Kluyveromyces lactis shows no formylglycine modification and has no enzyme activity. Applied Microbiology and Biotechnology, 102(6), 2709-2721. https://doi.org/10.1007/s00253-018-8828-5.

Sunds, A. V., Rauh, V. M., Sørensen, J., \& Larsen, L. B. (2018). Maillard reaction progress in UHT milk during storage at different temperature levels and cycles. International Dairy Journal. https://doi.org/10.1016/j.idairyj.2017.08.008.

Tossavainen, O., \& Kallioinen, H. (2007). Proteolytic changes in lactose hydrolysed UHT milks during storage. Retrieved from Milchwissenschaft, 62(4), 410-415. http://cat. inist.fr/?aModele $=$ afficheN\&cpsidt $=19123002$.

Troise, A. D., Bandini, E., De Donno, R., Meijer, G., Trezzi, M., \& Fogliano, V. (2016). The quality of low lactose milk is affected by the side proteolytic activity of the lactase used in the production process. Food Research International, 89, 514-525. https://doi org/10.1016/j.foodres.2016.08.021.

Troise, A. D., Wiltafsky, M., Fogliano, V., \& Vitaglione, P. (2018). The quantification of free Amadori compounds and amino acids allows to model the bound Maillard reaction products formation in soybean products. Food Chemistry, 247, 29-38. https:// doi.org/10.1016/J.FOODCHEM.2017.12.019.

Valero, E., Villamiel, M., Miralles, B., Sanz, J., \& Martínez-Castro, I. (2001). Changes in flavour and volatile components during storage of whole and skimmed UHT milk. Food Chemistry, 72(1), 51-58. https://doi.org/10.1016/S0308-8146(00)00203-X.

Van Boekel, M. A. J. S. (2001). Kinetic aspects of the Maillard reaction: A critical review. Nahrung - Food, 45(3), 150-159. https://doi.org/10.1002/1521-3803(20010601) 45:3<150::AID-FOOD150 > 3.0.CO;2-9.

van Boekel, M. A. J. S. (2006). Formation of flavour compounds in the Maillard reaction. Biotechnology Advances, 24(2), 230-233. https://doi.org/10.1016/J.BIOTECHADV. 2005.11.004.

Vazquez-Landaverde, P. A., Velazquez, G., Torres, J. A., \& Qian, M. C. (2005). Quantitative Determination of Thermally Derived Off-Flavor Compounds in Milk Using Solid-Phase Microextraction and Gas Chromatography. Journal of Dairy Science, 88(11), 3764-3772. https://doi.org/10.3168/jds.S0022-0302(05)73062-9.

Wu, G., Bazer, F. W., Burghardt, R. C., Johnson, G. A., Kim, S. W., Knabe, D. A., \& Spencer, T. E. (2011). April). Proline and hydroxyproline metabolism: Implications for animal and human nutrition. Amino Acids, 40, 1053-1063. https://doi.org/10. 1007/s00726-010-0715-z.

Zhao, D., Le, T. T., Larsen, L. B., Nian, Y., Wang, C., Li, C., \& Zhou, G. (2019). Interplay between Residual Protease Activity in Commercial Lactases and the Subsequent Digestibility of $\beta$-Casein in a Model System. Molecules, 24(16), 2876. 